\title{
High quality in primary humanities: Insights from the UK's school inspectorates
}

\author{
Simon Catling \\ Oxford Brookes University
}

\begin{abstract}
The school inspectorates of the four jurisdictions of the UK are sources of evidence about the quality of humanities teaching, learning and curriculum in primary schools. The term 'humanities' usually refers to the subjects of geography, history and Religious Education, but here they are considered holistically, not separately. Discrete subject and inter-subject humanities inspection reports are used to identify what inspectors report to be high quality practices in this curriculum area. Six themes are presented, which reveal that: the best humanities curricula are based on subject and cross-subject ideas and connections, with subject learning clearly visible; flexible but rigorous approaches to planning enable progression in children's learning; strong teacher-child and teacher-humanities relationships reflect teachers' evident enthusiasm, commitment and expectations; teachers use a diverse range of approaches and resources; active and enquiry-based learning approaches engage children in developing their studies; and strong humanities leadership and explicit emphasis in school development priorities underpin high quality primary humanities. These features reflect the skills and qualities of expert primary teachers.
\end{abstract}

Key words: Primary humanities, high quality, school inspections, geography, history, religious education, expert teachers

\section{Introduction}

The UK's four government Education Departments rarely use the term 'humanities'. In inspection reports about primary school curricula the word is elusive. In England's primary schools often there are humanities subject leaders, giving the impression of a discrete curriculum area. Their responsibilities normally include oversight of the subjects of geography, history and, possibly, Religious Education, though this third subject may be led separately. England's primary curriculum subject structure and its inspections list geography, history and Religious Education individually, reflecting a policy approach to distinguish and differentiate between these subjects. In Scotland geography and history are named within the 'social studies' curriculum alongside societal, economic and political studies, but Religious and Moral Education is separate. In Northern Ireland 'The World Around Us' area of learning covers geography, history, science and technology, with Religious Education identified separately. The term 'humanities' is being introduced in Wales as an area of learning and experience encompassing geography, history and Religious Education, with politics, economy, society, culture and beliefs (Donaldson, 2015). It replaces 'Knowledge and Understanding of the World' for 3-7 year olds and the separate subjects of geography, history and Religious Education in Key Stage 2. Each nation identifies geography, history and Religious Education singly or linked, at times connected with other subjects or areas of learning. These humanities subjects focus on understanding and explaining people's lives, societies, places, environments, values, attitudes, beliefs, the past, the present, and in relation to the future. 
This article focuses on inspectors' judgments of high quality teaching, learning and curriculum in the primary humanities across the UK. It draws on national subject and curriculum area inspection reports. Intentionally, it considers only what inspectors identify as exceptional or outstanding practice, relating this where possible to insights from research. It takes a holistic view across geography, history and Religious Education and across the UK. Thus these subjects are not considered separately, and the four nations are neither distinguished nor compared. Achieving common ground across the subjects and jurisdictions is the focus. The four nations' education systems are very different in nature and scale (Brock, 2015), with England having much the largest population and the majority share of the UK's primary schools, but the value in looking across the countries is to explicate a shared sense of the most effective practice. There is limited material from inspections in Northern Ireland, Scotland and Wales, and much of the material in England is subject specific, so the focus is on inter-relating what reports state. Differentiation between Key Stages 1 and 2 is not emphasised, but where it is relevant it is highlighted.

This overview emphasises the features of teacher expertise and high quality provision in the primary humanities that inspectors have reported. Eaude (2012) describes expert primary teachers as 'prototypical' because they demonstrate expertise in a wide variety of ways, which seem individual to each teacher. Such expert teachers are 'situated' in their class and school context. Specific examples given by inspectors tend to reinforce this perspective. Teachers' expertise appears connected to the children they teach and is argued to be 'tacit', so not easily described. Yet, since inspectorates examine a curriculum area across schools, can shared and consistent features be identified? This examination of UK-wide inspection reports has sought to identify the features of expert teaching and learning. It may be that such features are generic to a primary teacher's pedagogic repertoire (James \& Pollard, 2012) or are humanities specific.

While subject and cross-subject dimensions have been extolled, and advice-rich publications have been available in recent years (such as Ashley, 1999; Barnes, 2015; Grigg \& Hughes, 2013; Hoodless et al., 2009; Kerry, 2015; Pickford, Garner \& Jackson, 2013; Reynolds, 2014), there has been little reported research about the primary humanities curriculum, learning and teaching (Brophy, Alleman \& Knighton, 2009; Monk \& Silman, 2011; Rowley \& Cooper, 2009). Inspection subject and curriculum area inspection reports offer evaluations and reflections, but no overview of primary humanities subject inspections has appeared. Examining inspectors' views of subject and curriculum areas explores a source to provide some insight into expertise in primary humanities.

\section{Reporting on the humanities in primary schools}

The curriculum structures of the UK's nations provide different contexts for inspecting the humanities and its subjects. In two nations inspectors have examined their Social Studies and The World Around Us [WAU] curricula (Education Scotland, 2013; H.M.I.e., 2007; E.T.I., 2014). Northern Ireland's primary school findings distinguish subjects within WAU, and in Scotland findings about primary and secondary social studies are likewise identifiable within the curriculum area reports. Religious and Moral Education is reported on separately in Scotland (Education Scotland, 2014), but in Wales and Northern Ireland no inspection overview of primary 
Religious Education is available. Inspection reports on primary geography and history have not appeared in Wales, while in England each humanities subject has been reported on individually. Even where primary schools have connected the humanities subjects in cross-curricular and creative curriculum topics, inspections maintained their subject focus for reporting (Ofsted, 2007, 2008, 2010, 2011, 2013a), using subject specific criteria (eg Ofsted 2013b, 2013c, 2013d). Subject reports comment on the contexts of their teaching but most do not provide an overview of such contexts nor interrelate the humanities subjects. The UK picture, therefore, is varied and incomplete.

Inspection evidence from those humanities subject reports produced between 2003 and 2014 which identify aspects of 'high quality' is the source material for this insight. It has drawn on other inspection reports where there is evident overlap with the humanities. In Northern Ireland and England sustainable development education has been investigated in primary schools (E.T.I., 2010; Ofsted, 2009), while in Wales sustainable development and global citizenship in Key Stage 2 has been a focus (Estyn, 2014). In Scotland and England inspections examined citizenship in primary schools (H.M.I.e., 2006; Ofsted, 2013e). All the inspection surveys used sample studies of primary schools. In Scotland and Northern Ireland geography and history were investigated in the same primary schools, but in England the sampling took place in different primary schools for the three humanities subjects. This article does not draw on inspection reports of individual schools, not least because the humanities subjects are not usually emphasised in these.

In reporting on the quality of subjects and curriculum areas in primary schools, inspectors makes judgements about curriculum and teaching quality, children's learning and achievements, and leadership and management. This overview focuses on judgements made of high quality practice, identified from inspectors' use of terms such as 'very good', 'outstanding' and 'best' to identify the calibre of the practices they observe. While England's reports explicitly refer to 'outstanding' work, reports in Northern Ireland and Scotland tend to refer to 'good and better' quality with occasional references to 'best practice'. Across the UK's inspection reports the highest quality humanities practice is found in just five to ten percent of primary classes and schools. To maintain the flow of the text, and to avoid continuous reference to inspection documentation, reports are not identified except where necessary.

\section{Themes in high quality primary humanities}

Subject and thematic inspection reports nationally use a format and style which aims to take an objective stance to describe and characterise what is observed. The identification of consistent features of very effective primary humanities has emerged through cross-comparison of the reports. In identifying the knowledge, skills and qualities which expert teachers use to provide, enable and enhance high quality humanities practices, six themes are highlighted. These cover: subjects in the humanities curriculum, planning for humanities, commitment to humanities, varied humanities teaching, stimulating humanities learning, and direction and development in humanities leadership.

\section{Appreciating subjects in the humanities curriculum}


Essentially, inspectors identify two contexts for humanities teaching across the UK. There is discrete, single subject, teaching of geography, history and Religious Education in some schools, while others use an integrated or cross-curricular approach in which one, two or all three humanities subjects (at times with others) are involved. The second context is more common. A feature of a high quality humanities curriculum is that one humanities subject leads as the organisational focus, even where there may be contributions from other subjects. Teachers ensure the visibility of the humanities subjects to children, noting that clarity about the nature and roles of subjects is central to high quality teaching and learning. This enables children to recognise and develop their subject understanding, which is noted to be particularly important in cross-curricular themes and topics.

Most learning is planned through topics linked to specific [i.e. curriculum] organisers. Examples include the Victorians, volcanoes or children's rights. Increasingly social studies is being delivered through interdisciplinary learning approaches around a relevant or topical issue, for example the Battle of Bannockburn or tourism in the locality. This is most effective when its sits within a balanced and coherent whole school programme. (Education Scotland, 2013, 6)

UK-wide inspection reports support the finding from a long-term study of one USA elementary school teacher's work, where it was evident that the 'big ideas' of the social studies subjects were vital in helping children to engage at a high level with the those subjects (Brophy, Alleman \& Knighton, 2009). Curriculum clarity about and explicit reference to humanities subjects are vital for children to know that they are focusing on particular subject perspectives and content. Children benefit when they know that they are using the 'lens' of a specific humanities subject, and are engaged with it in their learning. In this way they begin to appreciate the humanities subjects and to understand why they matter. Inspectors reinforce that subjects have discrete identities and ways of investigating and reflecting on the world. They note, too, that high quality curricula and teaching draw on the cross-subject aspects of the humanities - concepts such as community, similarity and difference, continuity and change, cause and consequence, values and power - with these 'big ideas' developed in both subject and cross-curricular contexts.

A high quality humanities subject and cross-subject curriculum enables primary children to begin to make sense of the places, times and societies in which they and others live, today and in the past, and in possible futures. Such curricula introduce them to connections and comparisons between their own and others' lives in similar and contrasting belief systems, places and communities, nationally and internationally. Through each subject's contribution children are introduced to, become aware of, and learn to apply concepts, ideas and insights in, across and beyond the humanities. This involves children using skills to examine different perspectives and complex, challenging and contentious ideas, learning about different viewpoints and making judgements. Clarity about humanities subject contributions helps children appreciate their relevance and apply them to their own lives and outwardly to others. One subject context speaks for other humanities subjects:

In best practice [in Religious and Moral Education], teachers are clear that their role is not just about imparting knowledge but is also about 
accompanying, challenging and guiding children and young people in this personal search [for meaning, value and purpose in life]. (Education Scotland, 2014, 9)

Inspection reports noted that in planning for and teaching the humanities subjects expert teachers are knowledgeable about the subjects and may be very well-informed in more than one, enabling them to use their understanding to children's advantage. Teachers were knowledgeable, too, about pedagogy appropriate for the subject.

Particularly effective practice was characterised by teachers who not only had good subject knowledge but also good subject pedagogy, that is, good understanding of how pupils learn the subject. (Ofsted, 2011b, 53)

Inspectors found that very effective teachers of the humanities knew their own subject and pedagogic strengths and limitations, and were likely to seek to build on and address these. They were knowledgeable about their own understanding of the interconnections across the humanities and applied this in their teaching.

The first theme identified here concerns clear identification of the subjects of geography, history and Religious Education to promote each subject's key ideas, concepts and insights and ensure that children can best understand the humanities as such and appreciate their value. This is based in teachers' understanding and knowledge of these subjects and clarity about the connections and distinctions between them, including their complexity and the challenges inherent in their study. Such teachers enable high quality humanities learning.

\section{Planning for humanities: progression and meaning}

The most effective teachers plan their humanities subjects or cross-subject studies for progression in learning within topics and across the year from one topic to the next. They ensure evident and strong links between topic plans, the year's curriculum and a school's overall scheme of work to show how children's learning is expected to progress. The planning integrates ideas, content and skills in and across the humanities so that they are mutually supportive.

In the best planning, there is clear progression in the children's skills and concept development as well as in the associated factual content across each of the contributory strands; the connected elements of WAU [World Around Us] are interwoven skilfully into the activities and tasks...[to]...engage children's curiosity and interest. (E.T.I., 2014, 23)

Inspectors found that the best humanities curricula often extended beyond national guidance and requirements, were adapted for the school's community, and usually were enriched. Topics (or dimensions) such as migration, identity, poverty and wealth, global learning and citizenship, sustainability and local impact were included in the humanities curriculum. These supported children's understanding of the complexities of their own and the wider world and involved them in examining sensitive and controversial matters.

A few schools have recognised the close links between geography and education for sustainable development. In some schools there has been 
extensive work on global interdependence from a variety of perspectives. By looking at trade in a particular commodity, such as bananas or chocolate, pupils can understand how consumer choices affect individuals and environments around the world and develop an awareness of the complexity of international trade. The idea of 'global footprints' is used effectively in some geography lessons to raise awareness about how people can improve the environment or damage it, allowing pupils to measure their own use of resources and consider the wider implications. Pupils can learn that they can influence and change their local environment and influence the global environment for the better. (Ofsted, 2008, 15)

High quality humanities topics and lessons are meaningful to children and positively affect their learning. The best planning helps children develop good understanding through a balance of current affairs and places, a variety of religious and belief systems, and different past societies, circumstances and events, to broaden and deepen their knowledge. Expert planning and teaching sustain learning through extended lesson times, and by blocking topics across several weeks, increasing time for depth of study. This requires flexibility in curriculum thinking to support emergent direction of learning. The best teachers appreciate such developments and see them as worth pursuing. Effective mutually supportive cross-curricular links are made appropriately with literacy, science, mathematics, art, drama and other subjects. This approach enables children to focus, extend and deepen their learning, because they have opportunities to investigate and reflect on their studies.

This second theme highlights the centrality of planning based in subject and crosssubject ideas, at the heart of which is progression in children's learning. Key to this is the relationship between whole school planning in the humanities with year group, topic and lesson planning. In subject and cross-subject topics the focus is on clear learning about and within the topic. Such planning is not rigid but thoughtfully responsive and capable of engagement with other subjects. Flexibility is important to expert teachers, who provide a clear structure but are open to new lines of investigation to pursue what is likely to give children greater insight and understanding.

\section{Humanities commitment: enthusiasm, expectations and relationships}

Inspections identified that a key aspect of high quality humanities education is that teachers value, and have enthusiasm for, the subjects and their inter-connections. Their positive attitude and approach engenders children's curiosity and interest and fires children's imagination, stimulating their learning. The most effective teachers of humanities hold high expectations of their children and ensure that their strengths and needs are supported and challenged. This leads to well-motivated children who develop positive attitudes to the humanities, enjoy them and look forward to their studies.

Inspection reports highlight that well-grounded and positive relationships and interactions between teachers and children underscored very effective humanities teaching. Inspectors noted that expert teachers recognised the understandings and experience which children bring to their humanities topics and use in wider social contexts within class and school. This perspective is reinforced in reviews of aspects of research into social studies teaching and learning in the USA (Levstick \& Tyson, 
2008). Particularly, inspectors note this in teaching about citizenship and sustainable development across the UK.

The third theme is teachers' commitment to the humanities, which is fundamental to children's positive attitudes and learning. This is strongly linked with positive relationships and interactions between teachers and children. Such teachers hold high expectations of their children in humanities learning. The expectations and challenge teachers provide through their knowledge of their children is essential to how, and how well, the children learn.

\section{Varied humanities teaching: a teacher's repertoire}

Inspectors noted that expert teachers of humanities use varied teaching methods which involve children in practical activities, rational and creative responses and reflection to generate depth in thinking and understanding. The best teachers of humanities therefore employ a wide ranging repertoire of approaches and resources. These include observing and handling artefacts and objects; reading, hearing and telling stories; undertaking studies outside the classroom and school through fieldwork and in visits to museums, heritage sites and places of worship; meeting and questioning experts on site and in school; discussion and debate; constructing and reconstructing situations through drama, role play and enactment; and model making and art. Even within a subject topic, teachers draw on the potential of other subjects. They match approaches to topics and learning needs. Kelly (2003) identified that children's deeper learning in one humanity topic came about when they made enquiries using artefacts and drama-based exploration of the lives of a Saxon community. Similar outcomes emerged in studies of children's humanities subject and cross-subject learning in case studies described by Rowley and Cooper (2009).

The most effective humanities teachers use a variety of suitably evocative and thought-provoking resources to support and stimulate learning. Effective resources include the outside environment and classroom materials, creative and challenging applications of new technologies, such as digital film and photography, data handling and analysis, internet sources and presentation programmes. The best teaching enables children to learn to select, analyse and synthesise relevant and appropriate information, and to discriminate between informative, limited and opinion-based sources.

Expert humanities teachers address their children's interests, strengths and weaknesses. They identify clear subject and cross-humanities outcomes and ensure they are accessible to, and comprehensible by, all children. Learning is effectively sequenced within and across lessons and encourages systematic critical thinking. Such teachers are identified as using high level questioning consistently, spotting children's alternative conceptions and misunderstandings readily and quickly, and then tackling these. The best teachers challenge children to develop their humanities work more deeply, providing opportunities for children to consolidate their knowledge and understanding in and between the humanities subjects. High quality teaching involves engaging activities and constant dialogue with children to scaffold and embed humanities subject and cross-subject understanding (Brophy, Alleman \& Knighton, 2009). This is reflected in this comment by inspectors, which applies across the humanities: 
Where achievement in history was outstanding, by the time they had completed primary school, pupils could evaluate a range of historical sources and make perceptive deductions about the reliability of historical sources in answering historical questions. They had gained an understanding of change and continuity, and they understood the significance of people in a wider historical context. They could identify anachronism - and were aware of different views about the events they had studied. They used historical terms accurately and could make pertinent and valid comparisons between periods. (Ofsted, 2011b, 10)

Inspection evidence notes that in the best humanities practices, teachers ensure that assessment foci, criteria and approaches to learning are clear to the children. They apply them consistently, and children know what is being assessed, why, when, how and where it might lead. Varied approaches are used, with teacher assessment alongside self and peer assessment. In plenary sessions discussions consider what is being learnt and understood in the context of previous learning, noting for all children how their learning is developing. Regular formative assessments are central, with high quality feedback discussing and identifying next steps about what to address or where to develop. Good teacher records are important to tracking and planning for teaching for progression.

The fourth theme identifies that the 'width and balance' of teaching employed by high quality teachers enables them to meet their children's learning needs. Such teachers challenge their children through the use of informed and focused questioning and dialogue to enable effective learning, the resolution of misunderstandings and gains in clarity. They use a wide repertoire of approaches and resources to enable children to explore their studies and investigations in depth, and listen to children's perspectives on their learning, which entails consistent interaction and feedback.

\section{Stimulating humanities learning: open, active and challenging enquiry}

Inspectors report that young children's learning in the humanities should be based on active engagement and enquiry. This is developed when teachers encourage curiosity and use questioning, investigations, hypothesising and problem solving, while balancing teacher-led and child-initiated learning. Inspectors noted that children learn best when working co-operatively in pairs and teams, balanced with independent studies, an approach which underpins a strong 'learning community' (Brophy, Alleman \& Knighton, 2010).

Enquiry learning requires a clear sense of direction in which children pursue valid lines of investigation, framed and negotiated between them and their teacher. Such investigations are usually based in initiatives inspired or instigated by the teacher, or by the children themselves. Children are encouraged to express and justify their reasons, arguments and viewpoints and are included in decision-making, an approach identified in very effective citizenship teaching (Estyn, 2014; H.M.I.e., 2006; Ofsted, 2013e). Expectations are broad and high to encourage children to challenge and stretch themselves; they are flexible so that children can pursue their own needs and initiatives. This is an open approach to learning. As one inspection report states:

Children told us they enjoyed their [WAU] learning when:

- It is hands-on and contains learning by doing; 
- It involves art and creativity;

- They contribute to the planning and get to make choices and ask questions;

- They detect the teacher's enjoyment and enthusiasm;

- The learning is flexible and responsive to their suggestions and interests;

- They are able to work in groups, negotiate and take responsibility for their own decisions and actions; and

- They are able to turn their mistakes into opportunities for further learning. (E.T.I., 2014, 20)

The best humanities teaching helps children consider and distinguish effectively the reliability of evidence, fact and opinion, helping them identify and compare different and conflicting viewpoints. Children have time to think for themselves and 'feed in' their perspectives for others to consider. In this way they learn to engage with humanities thinking as young investigators in geography, history and Religious Education. This leads to children developing the confidence and skills to express their personal views and feelings on matters, concerns and issues that are real to them, in a secure and supportive environment. Through high quality teaching children have opportunities to examine - via role play or for real situations - responsible actions which are stimulated by a topic. For instance,

Where RE was most effective at Key Stage 1, pupils began to develop a framework of understanding within which to locate their learning in RE. Their questions became increasingly perceptive and they started to undertake their own independent investigations. They related their learning to their experience, finding parallels between features of religion and belief and their own lives. They also began to explain the role which stories and practices play in the lives of believers. When they had the opportunity to use their imagination and engage with high-quality resources, they often offered very thoughtful insights. (Ofsted, 2010, 11)

The elements of curiosity, risk taking and problem-based topics and tasks appear to underpin children's best humanities learning. Monk and Silman (2011) describe several case studies in which children's curiosity and inquisitiveness was tapped into to motivate them to pose or refine their own questions for investigation. This involved an open-ended approach to where the direction of such explorations was not tightly defined; it entailed some risk but was an invaluable strategy for stimulating humanities learning, enabling understanding to blossom. Humanities inspection reports reinforce this view. A problem-oriented approach to enquiry is demanding, but children enjoy and respond to the challenge. The benefit is that through dialogue with peers, their teacher and other adults, children consider several ways to view and identify alternative solutions to a problem they are addressing. This helps them recognise that there are not often comfortable, simple or singular outcomes and that these can be controversial.

Children and young people often demonstrate strong awareness of their responsibilities for the environment both now and in the future. Older children in primary schools... say this way of learning [through learning in the outdoors] challenges them to think about the relationship between humans and 
other living things. They can talk about the consequences of natural events and humankind's impact on the world and reflect on how this links to ethics and morality. (Education Scotland, 2014, 14)

In high quality humanities teaching, fieldwork, off-site visits and visitors to class are integrated into the topics studied. Children devise questions and areas to investigate in preparation for, and to follow-up such visits, frequently leading developments. Such enquiry-based practice brings humanities topics to life, provides new and engaging sources of information and perspectives, and broadens experience. These approaches motivate and initiate new learning, while enriching understanding of prior learning.

Such stimulating learning contexts help children to build and use subject specialist vocabulary. This supports and enriches listening and speaking skills, and enhances children's extended descriptive and explanatory writing. Often learning is extended through links, for instance, with mathematical and scientific learning and in the arts, helping children appreciate the humanities' wider social and cultural links. Children also develop the capacity to make good use of accounts, reasoning and explanation when conveying and communicating their findings in various ways.

Children often use their numeracy skills to illustrate results of their surveys about religious beliefs, other viewpoints and practices and traditions. They apply knowledge of percentages and fractions when working with population data and engage in problem solving activities for example when exploring ethical issues such as Fair Trade. (Education Scotland, 2014, 21)

The fifth theme highlights that high quality humanities learning is often active and enquiry-based. Children are encouraged to construct, interrogate, analyse, communicate and evaluate their investigations, which requires them to be systematic, thoughtful, creative and reflective in their work. It also calls upon them to employ the subjects' concepts, content, skills and appropriate sources and resources. Teachers must fully understand and appreciate what their children are learning, have learnt, where they are going educationally and what will help them achieve progress.

\section{Direction and development in humanities leadership}

Inspectors state that clear leadership and management are essential for highly effective humanities teaching, learning and curriculum development in primary schools. Fundamental to this is the interest and support of the head teacher. Where humanities teaching is very effective teachers with responsibility are invariably enthusiastic, knowledgeable and articulate about the humanities. They appreciate the distinctiveness of, and connections between, each humanities subject, their place in the curriculum, and what is needed to maintain and develop high standards and achievements in children's learning. Such schools have clear statements of the value of the humanities and its subjects. They set out the purpose, coverage and approach to their curriculum, teaching and learning, possibly linked with sustainability, citizenship, global learning and out-of-classroom policies. Humanities vision statements identify the topics and progression through the school and its assessment practices. They give clear advice for planning and the development and revision of medium term plans, and provide for flexibility, innovation and responsiveness. An expert humanities leader can have an impact which permeates the whole school 
through extra-curricular activities, such as eco and fair trade clubs, perhaps using school community connections and involvement (Estyn, 2014). For example,

This school has organised a number of activities including a mini-forest project, generation of wind power, archaeological excavations and the rearing of trout eggs. Work has included setting up a website about local trees and planting 2000 trees on the school's grounds. An ongoing project is to set up an area of willow production. The pupils have been involved at every stage. An integral part of the project has also been to highlight the importance of conserving forests and reducing dependence on fossil fuels. Through environment art pupils have increased the amenity value of the site for the community. Through working together with advisors from Scottish Natural Heritage, the RSPB and members of the local community they have produced something valued by the community and been able to add to the local economy. (H.M.I.e., 2006, 10)

A humanities leader's commitment is key. Undertaking regular personal subject and cross-curricular professional development is essential, often through making use of subject associations to keep up-to-date and for advice and guidance about resources, programme developments and new initiatives (either through school or personal membership). Such leaders monitor practice across the school and provide wellevidenced and improvement-focused directions for the humanities. This enables decisions about staff development, whether through whole staff sessions or individually and in small groups, both one-off and recurrent. The focus lies in consistently extending confidence through developing teachers' humanities knowledge and understanding to enhance pedagogy and children's learning.

An effective humanities leader uses action planning to develop and improve resources and undertake curriculum development to support children's progression and depth of learning. A noticeable impact is the high profile achieved for humanities education in schools, through the leader's capacity to engage and enthuse senior managers and colleagues, thus fostering a broad curriculum and high aspirations.

In the best practice, the co-ordinators monitored rigorously the quality of provision through, for example, regular reviews of teachers' planning and the children's books. They carried out well-focused classroom observations to monitor the quality of the learning and teaching. These co-ordinators also demonstrated teaching strategies to extend colleagues' skills and knowledge and held well-focused discussions with teachers about how to improve further key aspects of the provision. This work brought about greater confidence and purpose in the learning and teaching and supported continuous improvement in the schools' documentation. (E.T.I., 2014, 12)

The sixth theme emphasises that high quality humanities provision, teaching and learning reflects the impact of an expert humanities leader in a school - someone able to engage staff and raise expectations of children through support for them. This includes providing a clear vision for humanities which staff value. It is underpinned by evident encouragement and support by the senior management, fostered by the subject leader. The positive engagement of senior managers is important for resource 
access, staff development and recognising humanities learning and achievements throughout the school and beyond.

\section{Conclusion}

National inspection reports say much about high quality teaching and learning in the humanities. The humanities set of subjects - geography, history and Religious Education, at times with other social studies - are usually linked in primary schools, and explicitly conjoined in the revised Welsh curriculum (Donaldson, 2015). The humanities subjects' distinctive types of knowledge and procedures are manifested in their shared focus on the human dimension through people in places and environments, in time, and with beliefs and moral values - hence their grouping as 'humanities' subjects. They share a number of key ideas, which high quality teachers draw out. Across the UK, the humanities subjects are rarely inspected together, and they tend to be reported separately, even in curriculum area reports. The purpose here has been to seek what is shared across national school inspection reports about high quality curriculum, teaching and learning in the primary humanities.

Several features emerged. To teach the humanities well primary teachers need to be knowledgeable about its subjects and able to 'see' across them, having what Shulman (2003) characterised as pedagogic content knowledge [PCK]. PCK has a range of aspects beyond subject knowledge, fundamental as this is to high quality teaching. These include curriculum knowledge, pedagogical knowledge, knowledge of learners and knowledge of resources for teaching. High quality teaching practices in the primary humanities take into account the purpose of learning in the humanities and its subjects, what is distinct about each subject and what they share. It emphasises holding high expectations of children's learning, drawing on a wide repertoire of teaching strategies and approaches, using active and enquiry methods, appreciating the nature and range of resources that can be used, and understanding how best to enable learning for each child. Other important features are teachers' enthusiasm for, and awareness of the humanities in children's lives, alongside their flexibility in approach and risk-taking. Positive attitudes towards cross-school development in the humanities for children's learning are central to a school's vision for its children and to its effective leadership.

These features can be described as the underpinning characteristics of all high quality teaching, learning and curriculum (Alexander, 2010a, 2010b; Eaude, 2012; James \& Pollard, 2012). They are not particular to the primary humanities. What is essential for such teaching qualities to reach fruition is context - that the humanities are seen to matter in a primary schools and that holistically and as separate subjects, they are visible, valued and highlighted for teachers, children, parents and inspectors. These features, articulated from inspection reports, epitomise the best practices in primary humanities curriculum design, teaching and learning across the UK. Implementing and achieving these is a challenge for all primary schools.

\section{References}

Alexander, R. (2010a). Children, their World, their Education. Abingdon: Routledge. Alexander, R. (2010b). The Cambridge Primary Review Research Surveys. Abingdon: Routledge. 
Ashley, M. (Ed.) (1999). Improving Teaching and Learning in the Humanities. London: Falmer Press.

Barnes, J. (2015). Cross-Curricular Learning 3-14. [3 ${ }^{\text {rd }}$. Edition] London: Sage. Brock, C. (Ed.) (2015). Education in the United Kingdom. London: Bloomsbury. Brophy, J., Alleman, J. \& Knighton, B. (2009). Inside the Social Studies Classroom. New York: Routledge.

Brophy, J., Alleman, J. \& Knighton, B. (2010). A Learning Community in the Primary Classroom. New York: Routledge.

C.C.E.A. [Council for Curriculum, Examinations and Assessment] (2009).

Implementation of The World around Us.

www.ccea.org.uk/sites/default/files/docs/curriculum/area_of_learning/the_world_arou nd_us/implmentation_of_world_around_us.pdf. Accessed May 22016.

Donaldson, G. (2015). Successful Futures: Independent Review of Curriculum and assessment Arrangements in Wales.

http://gov.wales/topics/educationandskills/schoolshome/curriculuminwales/curriculu m-for-wales/?lang=en. Accessed February 32015.

Eaude, T. (2012). How Do Expert Primary Teachers Really Work? Exeter: Critical Publishing.

Education Scotland. (2013). Social Studies 3-18: Transforming Lives through

Learning.

www.educationscotland.gov.uk/resources/0to9/genericresource_tcm4817063.asp. Accessed May 72016.

Education Scotland (2014). Religious and Moral Education 3018: Transforming Lives through Learning.

www.educationscotland.gov.uk/Images/CurriculumImpactReviewRME_tcm4826574.pdf.

Estyn (2014). ESDGC: Progress in education for sustainable development and global citizenship. www.estyn.gov.wales/thematic-reports/esdgc-progress-educationsustainable-development-and-global-citizenship-june-2014. Accessed January 18 2016.

E.T.I . [Education and Training Inspectorate, Northern Ireland]. (2003). Provision for Geography and History in a Sample of Primary Schools in Northern Ireland. www.dera.ioe.ac.uk/5946/1/report-of-a-survey_provision-in-geography-and-historyin-a-sample-of-primary-schools-in-northern-ireland.pdf. Accessed March 112016. E.T.I (2010). Report of an Evaluation on Effective Practice in Education for Sustainable Development in a Sample of Primary, Post-primary and Special Schools in Northern Ireland. www.etini.gov.uk/index/surveys-evaluations/surveysevaluations-primary/surveys-evaluations-primary-2010/effective-practice-ineducation-for-sustainable-development-in-a-asample-of-primary-post-primary-andspecial-schools-in-northern-ireland.pdf. Accessed April 42016.

E.T.I. (2014). An Evaluation of the Implementation of The World Around Us in Primary Schools. http://www.etini.gov.uk/index/surveys-evaluations/surveysevaluations-primary/surveys-evaluations-primary-2015/an-evaluation-of-theimplemenation-of-the-world-around-us.pdf. Accessed May 72016.

Grigg, R. \& Hughes, S. (2013). Teaching Primary Humanities. Harlow: Pearson. H.M.I.e. [Her majesty's Inspectorate for Education] (2006). Education for Citizenship: A portrait of Current Practice in Scottish Schools and Pre-School Centres. www.dera.ioe.ac.uk/6352/. Accessed May 32016. 
H.M.I.e. (2007). Developing the four capacities through social subjects: Focusing on successful learners in primary schools. http://dera.ioe.ac.uk/9029/1/dssps.pdf. Accessed May 72016.

Hoodless, P., McCreery, E., Bowen, P. \& Bermingham, S. (2009). Teaching Humanities in Primary Schools. [ $2^{\text {nd }}$ Edition] Exeter: Learning Matters.

James, M. \& Pollard, A. (Eds.). Principles of Effective Pedagogy. Abingdon: Routledge.

Kelly, P. (2003). Student engagement in humanities classes. Paper presented at the British Educational Research Association Conference, Edinburgh, September. www.leeds.ac.uk/educol/documents/00003770.htm. Accessed May 62016.

Kerry, T. (Ed.) (2014). Cross-Curricular Teaching in the Primary School. [2 $2^{\text {nd }}$ Edition] Abingdon: Routledge.

Levstick, L. \& Tyson, C. (Eds.) (2008). Handbook of Research in Social Studies Education. New York: Routledge.

Monk, J. \& Silman, C. (2011). Active Learning in Primary Classrooms. Harlow: Pearson.

Ofsted (2007). History in the balance.

http://dera.ioe.ac.uk/7089/1/History_in_the_balance_(PDF_format).pdf. Accessed March 32016.

Ofsted (2008). Geography in schools: Changing practice.

www.ofsted.gov.uk/resources/geography-schools-changing-practice. Accessed December 122012.

Ofsted (2009). Education for Sustainable Development: Improving schools improving lives.

www.dera.ioe.ac.uk/1089/1/Education\%20for\%20sustainable\%20development.pdf. Accessed May 72016.

Ofsted (2010). Transforming Religious Education.

http://dera.ioe.ac.uk/1121/1/Transforming\%20religious\%20education.pdf. Accessed February 182016

Ofsted (2011a). Geography: Learning to make a world of difference.

www.gov.uk/government/uploads/Geography_-

_Learning_to_make_a_world_of_difference. Accessed March 172016.

Ofsted (2011b). History for all.

www.gov.uk/government/uploads/system/uploads/attachment_data/file/413714/Histor y_for_all.pdf. Accessed February 142014.

Ofsted (2013a). Religious Education: realising the potential.

www.gov.uk/government/publications/religious-education-realising-the-potential.

Accessed February 92014.

Ofsted (2013b). History survey visits: Generic grade descriptors and supplementary

subject-specific guidance for inspectors on making judgements during visits to

schools. www.ofsted.gov.uk/inspection-reports/our-expert-reports/history. Accessed June 42013.

Ofsted (2013c). Religious education survey visits: Generic grade descriptors and supplementary subject-specific guidance for inspectors on making judgements during visits to schools. www.ofsted.gov.uk/inspection-reports/our-expert-reports/religiouseducation. Accessed June 42013.

Ofsted (2013d). Geography survey visits: Generic grade descriptors and supplementary subject-specific guidance for inspectors on making judgements during visits to schools. Www.ofsted.gov.uk/inspection-reports/our-expert-

reports/geography. Accessed June 42013. 
Ofsted (2013e). Citizenship consolidated? A survey of citizenship in schools between 2009 and 2012.

www.gov.uk/government/uploads/system/uploads/attachement_data/file/413124/Citiz enship_consolidated.pdf.

Pickford, T., Garner, W. \& Jackson, E. (2013). Primary Humanities: Learning through Enquiry. London: Sage.

Reynolds, R. (2014). Teaching Humanities and Social Sciences in the Primary School. Melbourne: Oxford University Press.

Rowley, C. \& Cooper, H. (Eds.) (2009). Cross-curricular Approaches to Teaching and Learning. London: Sage.

Shulman, L. (2003). The Wisdom of Practice: Essays on Teaching, Learning and Learning to Teach. Hoboken, NJ: Jossey-Bass. 